\title{
PERMISSIBLE MEDICINE AND RATIONALIZATION OF HALAL PHARMACEUTICALS
}

\author{
ALZEER J. \\ Swiss Scientific Society for Developing Countries, Halalopathic Research Unit, Zürichstrasse 70, \\ Dübendorf, Switzerland. \\ *Corresponding author: jawad.alzeer@uzh.ch
}

(Received: 17 th. Aug. 2020, Accepted: $5^{\text {th }}$ Jan. 2021, Published on-line: $15^{\text {th }}$ Jan. 2021)

\begin{abstract}
Permissible medicine 'Halalopathy' represents a compatible relation between therapeutic drug and human beliefs/lifestyles. Production of permissible drugs is achieved by evaluating ingredients and monitoring the production process to be compatible with a certain specific standard depending on the requirement of the lifestyle or belief of the patient. When drugs and beliefs are compatible, a domino chain effect is generated, trust is developed and the placebo effect is stimulated. As a result, a compatible system between mind and medications is established, trust in the treatment is intensified, entropy is reduced, potential energy is enhanced and self-confidence is enriched. The compatibility concept is based on finding a connection between human's belief and therapeutic drug where certain genes will be turned off epigenetically. Halalopathic medicine represents a new therapeutic concept in which holistic values material, human, moral and spiritual values - are used to deliver the right treatment to the right patient.
\end{abstract}

KEYWORDS: Halal pharma; Integrative medicine; Effective treatment: Personalized therapy

\section{INTRODUCTION}

Human is healthy by nature, and the preservation of good health is essential to life and a fundamental need for human existence. The value of health has been expressed and addressed in different cultures through different perceptions, yet the consensus was widely shared that health is the crown that sits on the head of a healthy person, only patients can perceive. The primary mission of humans on earth is to contribute, through good work, towards a civilized society, and the pillars of civilization have been clearly described by the Messenger of Allah. "Whoever starts the day feeling secure, healthy, and has enough food for the day is as though he owns the whole world", (At- Tirmidhi). Health, food, and security play a key role in measuring and structuring the living standards of different societies. Health is a state of physical and mental comfort, and the preservation of health is a fundamental human right "Your body has a right over you", (Sahih al-Bukhari). Food is an organic need and crucial for our survival, whereas prevailing security can provide peace, happiness, and tranquility, hence the promotion of health, food, and security is an important element for building a civilized society. 
Illness is a temporary condition in which the body is no longer able to function collectively. The condition could worsen if the immune system is no longer able to cope or if unsuitable medication is used. Allah considered the man's body as a trust, need to be protected and kept in the best shape. Therefore, mankind is responsible to protect their bodies from any harm, risk, and disease. Many medical models have been developed to improve the therapeutic window and enable more effective treatment, (Garcia-Crespo et al., 2013; Attena, 2016).

Personalized therapy is a new option where many researchers are heavily involved to provide the right treatment for the right people at the right dose and time, (Rodriguez-Gonzalez, 2013). The need for a new medical trend to cope with increasing stress and to improve overall health and attitudes will continue to be a priority. Novel concepts must be postulated and implemented to improve therapeutic options, enrich personalized therapy, and provide appropriate resources for combating diseases.

The permissible medicine, Halalopathy, was introduced as a new medical model in which the ingredients and the process for producing the therapeutic drug are compatible with the individual's lifestyle, such as vegan, Halal, kosher, lactose-free, sugar-free, gluten-free and others. The goal of permissible medicine is to achieve more effective prevention and/or treatment, thereby improving the cost-effectiveness of the entire health system. Compatibility between reality and stored knowledge generates effective judgement, while compatibility between therapy and lifestyle generates effective treatment. Disease is a disorder, and entropy plays a key role in regulating the disorder. The creation of well organized, regulated and connected health care can provide a highly compatible system in which concept and behavior are well integrated. The compatible and highly ordered system will activate the potential energy which is vital for strengthening the immune system, stimulating the fighting mode and thus promoting prevention and/or cure. The permissible drug, which is compatible with lifestyle, increases trust and reduces entropy, which is essential to activate the placebo effect, increase potential energy and thereby activate the immune system. Reduction of entropy, creates favorable circumstances that operate synergistically with the prescribed medicines and promote healing towards complete recovery, (Alzeer, 2020; Alzeer, 2020a). Permissible medicine 'Halalopathy' can act as a source of education and motivation for patients to assume more personal responsibility for their health by adapting and enriching certain values to achieve more effective treatment. The compatibility of therapy and faith is controversial, (Sidani et al., 2009), yet this study aims to reflect deeply on the useful link between therapy and individual faith using the healing power of the word and tranquility in combination with therapeutic drugs for more effective treatment.

\subsection{The Concept of Cure in Islam}

Progresses in psychological, medical, and physiological research have led to views health and illness as the product of a multifactor including biological (e.g. genetic predisposition), behavioral, (e.g. lifestyle, stress, beliefs) and social factors (e.g. cultural influences, family relationships, and social support), (Short \& Mollborn, 2015). Previously the canon of medicine, Ibn Sina, said: Panic is half of illness, calm (tranquility) is half of the medicine, and patience is the beginning of the recovery, (Ibn Sina). According to Ibn Sina, creating tranquility 'favorable circumstances' before and during cure is essential for enhancing treatment. Tranquility is a state of no fear and no grief, more likely to occur in the presence of environmental features that are associated with peace and quiet, (Herzog \& Barnes, 1999). Tranquility is the phase in which the 
potential energy is maximum, while the state of minimum potential correlates with the state of fear 'anxiety' or grief 'depression'. Long-term fear and/or grief is painful for the heart and has no benefit for human health, consequently, the Qur'an introduced fear and grief in the form of a prohibition or a negation. "That is only Satan who frightens (you) of his supporters. So, fear them not, but fear Me, if you are indeed believers", (Al-Imran 3: 175). It is therefore recommended not to destroy happiness with sadness and not to corrupt the mind with pessimism. "those who say: Our Lord is Allah, and afterward are upright, the angels descend upon them, saying: Fear not nor grieve, but hear good tidings of the paradise which ye are promised", (Fussilat 41: 30). The Qur'an has recognized the concept of tranquility 'no fear, no grief' and attributed it to the state of optimism, positivity, and constructive expressions.

The Arabic definition of Islam is to acquire peace while submitting the will to Allah's recommendation. Islam highlighted the usefulness of constructive expressions 'good word' and tranquility as a powerful tool for promoting recovery. The contribution of 'positive expression' in cure is highlighted in Qur'an. 'O mankind! There has come to you good advice from your Lord, and a cure for that which is in your breasts, and a guidance and a mercy for the believers", (Yonus 10: 57). The contribution of tranquility in cure is highlighted twice in Qur'an "We reveal the Qur'an which is a cure and mercy for the believers but does nothing for the unjust except to lead them to perdition”, (Al-Isra' 17: 82), “...Say, it is, for those who believe, a guidance and cure. And those who do not believe, in their ears is deafness, and it is upon them blindness. Those are being called from a distance place", (Fussilat 41: 44). Both elements 'Tranquility \& Constructive expression' pave the way toward creating favorable circumstances for promoting cure, but not enough to eliminate the disease completely. Subsequently, Qur'an introduced the third element, therapeutic agent 'Permissible drug', and described honey and its sources as a cure and a source of cure, respectively. "Then you (Bees) shall eat from flowers and fruits, so seek the path your Lord has made easy. There comes out of their (Bees) bellies a drink of different colors, wherein is a cure for mankind", (Al-Nahle 16: 69). Honey, the cure, is naturally derived from flowers and fruits (natural products), thus Islam highlights flowers and fruits as a source of medicine (Figure 1).

To avoid disease transmission, Qur'an listed what is not eatable and how to process eatable food, by utilizing the concept of Halal-Tayyab, (Alzeer et al., 2018) "O mankind, eat of the good and lawful things on earth and do not follow the footsteps of Satan. Indeed, he is to you a clear enemy”, (Al Baqarah 2: 168). From an Islamic point of view, tranquility is deeply connected with spirituality, "which is understood as a combination of positive emotions, a meaningful realization of the relationship with the Creator and a feeling of satisfaction and success'. Spirituality can be achieved by combining deeds with Allah's recommendations. The main goal of spirituality is to give hope and fill the heart with peace, (Kellert \& Farnham, 2002) and potential. Spirituality enriches tranquility and harmonizes the relation between concepts and behaviors and contributes significantly to a state of high potential.

The use of both the power of the word 'constructive expressions' and the tranquility that derives from spirituality can provide the favorable circumstances to promote healing and create a balanced mind, establish a state of inner peace and remind the patient that no one is protected from illness, the healing comes from Allah and every illness that Allah has created has a cure. "And when I am ill, it is He who cures me", (Al-Shuara 26: 80). The disease ends when the proper cure is applied, indicating that when the two opponents meet, proper remedy and disease, recovery from illness occurs: "Every illness has a cure, and when the proper cure is applied to the disease, it heals by Allah's Will", (Sahih Muslim). Over centuries, these statements have 
inspired Muslim scientists to strive for medical knowledge. In Islam, scientists and scholars appeal to Allah to grant

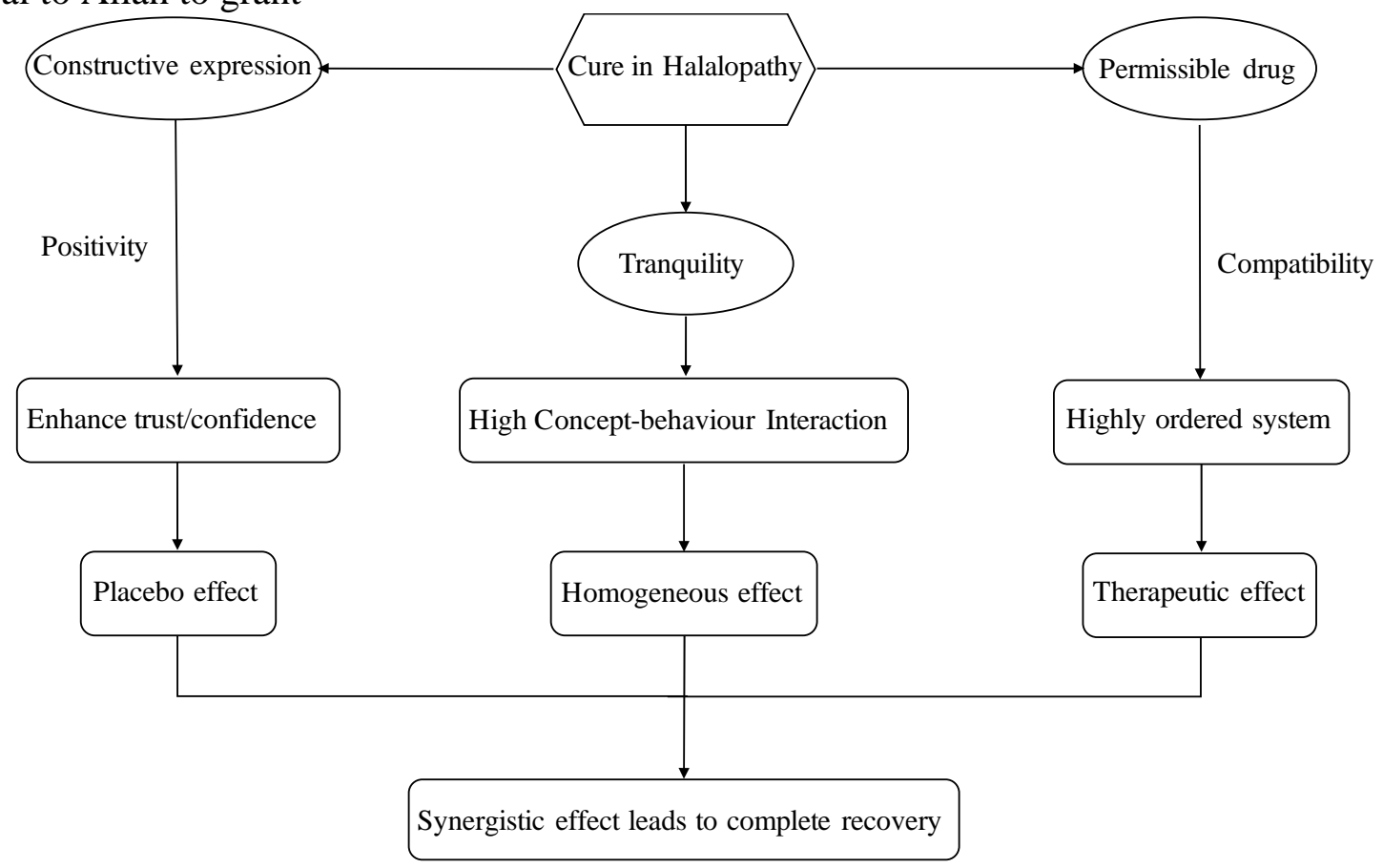

Fig. 1. The path of Halalopathy towards more effective treatment.

them the grace and power to search and develop a useful science that can be used as a voluntary, ongoing charity 'Sadaqa Jariyah'. Many believe that the reward for these acts is enormous to the extent that it can continue long after an individual's death, as long as the benefits of the act continue to be felt by others. In this context, Muslim scholars have developed a range of views of sciences in various fields such as medicine, chemistry, physics, astronomy and mathematics, and the work of Ibn Al-Haitham, Ibn Sina, Al-Biruni, Al-Khawarizmi and many others is still visible and is highly recognised and appreciated by many Muslim and non-Muslim scholars worldwide.

\subsection{Permissible Medicine}

Permissible Medicine or Halalopathy is a holistic and integrated form of medicine that aims to make the prevention and/or cure of diseases more effectively. This is accomplished by integrating the principles of naturopathy and allopathy and by taking into account the lifestyle good practices, (Alzeer et al., 2020b). Halalopathy combines the value of religion and lifestyles with the benefits of modern science, uses the comprehensive approach, and focuses on the curative power of the word and tranquility.

Halalopathic medicine from an Islamic point of view is based on the principle of HalalTayyib; it is absolutely free of all potential non-Halal ingredients, and Tayyib processes. The Tayyib concept represents a process that aims for maximum hygiene and minimum contamination. The ingredients involved in the process must be free of potentially toxic, najis (ritually impure) and khabith (unclean) substances, and all processes must comply with the Syari'ah, (Alzeer \& Abou Hadeed, 2016). The compatibility between therapy and human faith creates a more integrated and ordered system, it creates potential and a state of coexistence in 
tolerance. Consequently, the body's defense system is improved and tolerates the presence of foreign material, such as drugs, without an immune reaction, (Padela et al., 2016).

The implementation of the Halal-Tayyib concept requires the monitoring of the process and the evaluation of all ingredients involved in the production process, (Alzeer et al., 2018). The Halal-Tayyib label on the medicine will remind the patient of Allah, the healer, and strengthen the trust between patient, medicine, pharmaceutical companies, and doctors. "If Allah touches you with affliction, no one can remove it but Him. If He touches you with happiness, He has power over all things", (Al-Anaam 6: 17). The patient perceives that healing is compatible with the lifestyle, while the heart is filled with hope instead of despair, the soul and psyche are strengthened, (Asgharipoor, 2012), tranquility is intensified, creating favorable circumstances and likely contributing to more effective treatment. On the contrary, if a Muslim takes nonHalalopathic medicines, e.g. capsules made of porcine gelatin, incompatible and highly disordered system will be developed, the patient's heart will not be filled with tranquility; instead, stress, (Otto \& Paalzow, 1975) and stomach discomfort may occur, which is an unhealthy condition, (Deak et al., 2015) and may have a negative effect on the drug absorption, metabolism, (Konstandi et al., 2014) and excretion, ultimately weakening the immune system, (Adamo, 2016) and leading to less effective treatment, (Schneiderman et al., 2005). Incompatible systems is developed as a result of poor interaction between concept and behavior, which creates a sense of guilt and leads to high stress, ultimately to low potential.

Halalopathy contributes to personalized medicine, the right treatment for the right patient, therefore Halalopathy is not limited to Muslims. The use of medicines that may contain ingredients prohibited by religion (Buddhism, Christianity, Islam, Hinduism, and Judaism) is likely to cause patients to discontinue treatment, thus increasing the risk of a relapse of symptoms, eventually leading to prolonged hospitalization or death, (Sattar et al., 2004).

Previously, the selection of Halal-compliant drugs was not possible due to limited choices, however, as the number of non-animal pharmaceutical ingredients on the market increased, the opportunity to develop drugs that could easily be Halal-compliant became available, (Alzeer et al., 2020c). The Halal ingredient is not the only prerequisite for the production of a Halal product, but the production process, Tayyib, plays an essential role in determining the Halalness of the final product, (Alzeer \& Abou Hadeed, 2020d). Therefore, the Halal pharmaceutical product must first meet the requirements for toxicity, quality, and efficacy before it can be Halalcertified, (Ramli et al., 2012). Global recognition for Halal is important, and consumer awareness is necessary to educate consumers that Halal drugs are as high quality as their nonHalal counterparts. Yet, Muslims and non-Muslims alike have to deal with Halal products as effective and beneficial that do not compromise basic drug standards, (Norazmi \& Lim, 2015).

Halalopathy has been presented as a medical model where compatibility between the drug, the patient, and the lifestyle or belief is a key element in assuring a healthy life and/or enabling patients to receive more effective treatment. The effectiveness depends mainly on the enrichment of holistic values, which include material, moral, human, and spiritual values. The material value can be represented in the form of a rationally designed drug with potential therapeutic value. The human value is enriched by building trust between patient and doctor, having a positive expectation is a key step in the placebo effect. Moral value can be achieved by creating a compatible system between therapeutic drug and human lifestyle or beliefs, the compatibility system creates potential and activates the immune response. The spiritual value is based on the creation of a state neither fear nor grief, such a state develops peace, tranquility, and a state of high potential. Spirituality can be enriched when the interaction between concept and behavior is 
intensified, homogeneity prevails and a highly productive and potential state is being dominated. The placebo effect is not the only factor in the curative power of Halalopathy, but the key element is a synergistic effect in which every component contributes to the overall healing process and enhances the overall drug effect (Figure 1).

Halalopathic medicine needs further scientific research to determine its potential and implement it in clinical practice, however, pharma Halal standards need to be strengthened to ensure that all steps in the drug preparation are fully compliant with Halal and Tayyib requirements, including the source of all ingredients, safety, toxicity, manufacturing processes and packaging up to the point where the product reaches the consumer.

\subsection{The Concept of Cure in Halalopathy}

Potential energy and entropy are closely related, rising potential energy leads to a reduction of entropy and vice versa. Potential energy is created in the form of work, while entropy is scattered in the form of heat resulting from the random collision between molecules, inducing disorder, and disorganized energy. The disorder occurs when the cause-effect information is minimized, the concept-behavior interaction is reduced, and the inner compass is lost. Therefore, to enhance the potential, the concept-behavior interaction must be enriched, maximize the causeeffect information, and reduce the overall disorder.

The compatibility of concept and behavior is demonstrated in the form of a connection between mind and body. The mind has the power to rationalize an appropriate lifestyle or belief that could be compatible with human nature. Once faith is settled in the heart, it will turn into concepts that guide behavior in life to be selective in actions and specific toward goals. Being selective and specific increases focus reduces disorder, releases dispersed energy in the form of entropy and improves compatibility between mind and body (concept-behavior). Focusing increases the connection between mind and reality and concentrates efforts to improve performance and creativity, which in turn suppresses entropy and maximizes cause-effect information. Focusing maintains the organization, and differentiation of concepts, which is essential for optimal behavior that can respond to the environment.

Halalopathy has been presented as a new conceptual model for preventing diseases by controlling the entropic state ('a state of disorder') and/or treating diseases by applying the concept of permissible drugs, (Alzeer, 2018). Halalopathy is first to introduce the concept of entropy as a key element in the development and treatment of disease, (Alzeer, 2019). For the cases where entropy is increased, many of the settings have been changed; the non-covalent bonds are broken, the hydrophobic effect is affected, the rigid and native structure of macromolecules is transformed and increased with irregularity, while complexity, factuality, and sustainability are lost, water molecules are rearranged, the number of structures, conformations, rotations, microstates, and phases is increased, molecular movements became uncoordinated, random in all directions, and therefore it is fair to say that entropy creates an entirely new state with the destructive disorder, (Vorov et al., 2008). In recent years, many researchers have studied the human aging process and concluded that aging is a process in which the complexity and fractality of the anatomical structures and physiological processes are lost. Entropy has been used to quantify changes in fractality and irregularities, (Siciliano, 2017). Cognitive-behavioral therapy will help to reduce the entropic mental disorder and increase the potential energy that represents an additional energy source, (Irgens et al., 2017). According to the Halalopathy, the recovery is more effective if the entropy is reduced. It is accomplishable if a compatible system 
is set up between drug, patient, and mind, eventually the compatibility results in a system with higher-ordered and lower entropy. As potential energy and entropy are well connected, the reduction of entropy leads to an increase in potential energy, which in turn acts as an additive source of available energy. As the immune system senses the added energy, the patient's immune system is strengthened and, subsequently activates the fight mode, and if appropriate medication is given, a complete recovery can be achieved. However, if the patient fails to reduce entropy, the potential total energy may not be sufficient to activate the immune system and thus patient remains in hunt/flight mode.

Further research is needed to identify the potential of Halalopathy and to implement it in clinical practice. However, Halal standards need to be adopted to ensure that each step of the drug preparation is fully compliant with Halal and Tayyib requirements, including the source of all ingredients, the efficacy profile of the drug, the manufacturing processes, the packaging procedures involved before the product is delivered to the consumer. Under difficult circumstances Islam is adaptable and tolerable: If someone is forced out of necessity and without deliberate disobedience, there is no blame from the Islamic point of view. "But if one is forced by necessity, without willful disobedience, nor transgressing due limits, then he is guiltless. For Allah is Most Forgiving and Most Merciful", (Al-Baqarah 2: 173). Based on the Islamic principle of "necessities surpass prohibitions", many Muslim scholars allowed patients to use medicines from non-Halal sources only if the medicine was prescribed by a reliable doctor, the patient's life is in danger and there is no alternative medicine available.

Personalized medicine is generally perceived to ensure that the precise drug is produced with the right ingredients, formulated in the right dosage and administered to the right patient under the right circumstances. Patient expectations must be addressed and the development of the permissible drug is likely to add a unique value that matches patients' needs. Permissible medicine 'Halalopathy' was developed to provide a more effective drug by establishing a link between patient and the therapeutic drug, which can benefit billions of people, especially those who have a certain lifestyle or are allergic to certain foods. Harmony between drug and patient allows for the development of an ordered and compatible system and paves the way for more personalized therapy. Halalopathy offers added value to the consumer in terms of quality control and opens a new window for research to explore the role of entropy, potential energy and epigenetics in terms of strengthening prevention and/or improving cure to achieve complete recovery.

\section{CONCLUSION}

Demands of health are constantly increasing, systems and processes are becoming more complex. Health is an essential pillar in civilization, expand therapeutic options, and enrich personalized therapy is necessary to comply with public health demands. More efforts are needed to develop and implement new health care approaches for more effective treatment. Halalopathic medicine represents a new therapeutic option that utilizes material, human, moral, and spiritual values to provide the right treatment for the right patient. Significant amounts of highly critical ingredients are present in many drugs and their compatibility with the Halal status is questionable. Medicines labeled with 'Halal-Tayyib' are very appreciated and preferred by many patients, mainly in Muslim countries. The constructive expression 'Halal-Tayyib' is designed to assure the patient that the drugs have been produced under maximum hygiene, minimum contamination, and that the entire process is clean, pure, and Halal-compliant. This powerful and 
effective expression tends to create a pleasant feeling, reduce entropy, and facilitate the creation of favorable circumstances to promote more effective treatment. The development of drugs that are compatible with the Halalopathic principles paves the way for more personalized therapy.

\section{ACKNOWLEDGMENT}

We would like to thank Prof. Khaled Abou Hadeed, Farhan Tufail and Prof. Fawzi Al-Razem for useful discussion and support.

\section{FUNDING}

The author(s) received no financial support for the research, authorship, and/or publication of this article.

\section{CONFLICT OF INTERESTS}

The authors declare no conflict of interest.

\section{REFERENCES}

[1] Adamo, S.A. (2016). The stress response and immune system share, borrow, and reconfigure their physiological network elements: Evidence from the insects. Horm Behav., 88,25-30. https://doi.org/10.1016/j.yhbeh.2016.10.003.

[2] Alzeer, J., \& Abou Hadeed, K. (2016). Ethanol and its Halal status in food industries. Trends Food Sci Tech., 58,14-20. https://doi.org/10.1016/j.tifs.2016.10.018.

[3] Alzeer, J. (2018). Halalopathic: a new concept in medicine. J Mol Genet Med., 12(2),353. https://doi.org/10.4172/1747-0862.1000353.

[4] Alzeer, J., Rieder, U., \& Abou Hadeed, K. (2018). Rational and practical aspects of Halal and Tayyib in the context of food safety. Trends Food Sci Tech., 71,264-267. https://doi.org/10.1016/j.tifs.2017.10.020.

[5] Alzeer, J. (2019). Halalopathy: A science of trust in medicine. J Integr Med., 17(3),150154. https://doi.org/10.1016/j.joim.2019.03.005.

[6] Alzeer, J. (2020). Halalopathy: integrating mind, behaviour and health. Research OUTREACH. $\quad$ https://researchoutreach.org/articles/halalopathy-integrating-mindbehaviour-health/

[7] Alzeer, J. (2020a). Entropy and potential energy as a key role of Halalopathy in disease prevention and cure. Longhua Chinese Medicine, 3,20. https://doi.org/10.21037/lcm-2040

[8] Alzeer, J., Rieder, U., \& Abou Hadeed, K. (2020b). Good agricultural practices and its compatibility with Halal standard. Trends Food Sci Tech., 102,237-241. https://doi.org/10.1016/j.tifs.2020.02.025.

[9] Alzeer, J., Abou Hadeed, K., Basar, H., Al-Razem, F., Abdel-Wahhab, M., \& Alhamdan, Y. (2020c). Cannabis and its permissibility status. Cannabis Cannabinoid Res. https://doi.org/10.1089/can.2020.0017; in press.

[10] Alzeer, J., \& Abou Hadeed, K. (2020d). Halal Certification of Food, Nutraceuticals, and Pharmaceuticals in the Arab World. In: Laher I. (eds) Handbook of Healthcare in the Arab World. Springer, Cham. https://doi.org/10.1007/978-3-319-74365-3_36-1. 
[11] Asgharipoor, N., Farid, A.A., Arshadi, H., \& Sahebi, A. (2012). A Comparative Study on the Effectiveness of Positive Psychotherapy and Group Cognitive-Behavioral Therapy for the Patients Suffering From Major Depressive Disorder. Iran J Psychiatry Behav Sci., 6,33-41. https://doi.org/10.1080/17439760.2019.1663250.

[12] Attena, F. (2016). Limitations of Western Medicine and Models of Integration Between Medical Systems. J Altern Complement Med., 22(5),343-8. https://doi.org/10.1089/acm.2015.0381.

[13] Deak, T., Quinn, M., Cidlowski, J.A., Victoria, N.C., Murphy, A.Z., Sheridan, J.F. (2015). Neuroimmune mechanisms of stress: sex differences, developmental plasticity, and implications for pharmacotherapy of stress-related disease. Stress 18,367-380. https://doi.org/10.3109/10253890.2015.1053451.

[14] Garcia-Crespo, A., Alor-Hrnandez, G., Battistella, L., \& Rodriguez-Gonzàlez, A. (2013). Methods and models for diagnosis and prognosis in medical systems. Comput Math Methods Med,; ID 184257: https://doi.org/10.1155/2013/184257.

[15] Hadith (Sunan Al-Tirmidhi, 2346, Book 36, Hadith 43) șêp?

[16] Hadith (Sahih Al-Bukhari, 5199, Book 67, Hadith 133).

[17] Hadith (Sahih Muslim, 2204).

[18] Herzog, T.R., \& Barnes, G.J. (1999). Tranquility and preference revisited. Journal of Environmental Psychology 19,171-181. https://doi.org/10.1006/jevp.1998.0109.

[19] Ibn Sina, "Famous and well-known quotation described by Ibn Sina"

[20] Irgens, A.C., Hoffart, A., Nysæter, T.E., Haaland, V.Ø., Borge, F-M., Pripp, A.H., Martinsen, E.W. \& Dammen, T. (2017). Thought Field Therapy Compared to Cognitive Behavioral Therapy and Wait-List for Agoraphobia: A Randomized, Controlled Study with a 12-Month Follow-up. Front. Psychol., 8,1027. https://doi.org/10.3389/fpsyg.2017.01027.

[21] Kellert, S.R. \& Farnham, T.J. (2002). The Good in Nature and Humanity Connecting Science, Religion, and Spirituality with the Natural World, Island Press. https://doi.org/10.1016/S0362-3319(02)00270-7.

[22] Konstandi, M., Johnson, E.O., \& Lang, M.A. (2014). Consequences of psychophysiological stress on cytochrome P450-catalyzed drug metabolism. Neurosci Biobehav Rev., 45,149-67. https://doi.org/10.1016/J.NEUBIOREV.2014.05.0.

[23] Norazmi, M.N., \& Lim, L.S. (2015). Halal pharmaceutical industry: opportunities and challenges. Trends in Pharmacological Sciences, 36,496-497. https://doi.org/10.1016/j.tips.2015.06.006.

[24] Otto, U., \& Paalzow, L. (1975). Effect of Stress on the Pharmacokinetics of Sodium Salicylate and Quinidine Sulphate in Rats. Acta pharmacol toxicol., 36,415-426. https://doi.org/10.1111/j.1600-0773.1975.tb00809.x.

[25] Padela, A.I, Vu, M., Muhammad, H., Marfani, F., Mallick, S., Peek, M., \& Quinn, M.T. (2016). Religious beliefs and mammography intention: findings from a qualitative study of a diverse group of American Muslim women. Psychooncology 25,1175-1182. https://doi.org/ 10.1002/pon.4216.

[26] Ramli, N., Salleh, F., \& Azim, S.N. (2012). Halal pharmaceuticals: a review on malaysian standard, ms 2424:2012 (p). Journal of Arts and Humanities, 1,137-142. http://dx.doi.org/10.18533/journal.v1i1.13. 
[27] Rodriguez-Gonzalez, A. (2013). Methods and models for diagnosis and prognosis in medical systems. Comput Math Methods Med., 184257. https://doi.org/10.1155/2013/184257.

[28] Sattar, P., Ahmed, M.S., Majeed, F., \& Petty, F. (2004). Inert medication ingredients causing nonadherence due to religious beliefs. The Annals of Pharmacotherapy, 38,621624. https://doi.org/10.1345/aph.1D324.

[28] Schneiderman, N., Ironson, G., \& Siegel, S.D. (2005). Stress and Health: Psychological, Behavioral, and Biological Determinants. Annu Rev Clin Psychol., 1,607-628. https://doi.org/10.1146/annurev.clinpsy.1.102803.144141.

[29] Short, S.E., \& Mollborn, S. (2015). Social Determinants and Health Behaviors: Conceptual Frames and Empirical Advances. Curr Opin Psychol., 5,78-84. https://doi.org/10.1016/j.copsyc.2015.05.002

[30] Siciliano, R. (2017). Entropy as a method to investigate complex biological systems. An alternative view on the biological transition from healthy aging to frailty. Geriatric Care, 3,44-48. https://doi.org/10.4081/gc.2017.6755.

[31] Sidani, S., Miranda, J., Epstein, D.R., \& Bootzin, R.R. (2009). Cousins J. Moritz P. Relationships between personal beliefs and treatment acceptability, and preferences for behavioral treatments. Behav Res Ther 47: 823-9. https://doi.org/10.1016/j.brat.2009.06.009.

[32] Vorov, O.K., Livesay, D.R., \& Jacobs, D.J. (2008). Conformational Entropy of an Ideal Cross-Linking Polymer Chain. Entropy, 10(3),285-308. https://doi.org/10.3390/e10030285. 